\title{
Analysis of Just in Time Prerequisites in Iranian Car Assembly Plants
}

\author{
Hossein Yarahmadi ${ }^{1,}$, , Ali bohloli ${ }^{2}$ \\ ${ }^{1}$ The Tax Affairs Iran, City Tax Office of Doroud Iran, the Department of Accounting at the Payam Noor University, Doroud, Iran \\ ${ }^{2}$ Tax Administration Dorud City, Doroud, Iran
}

Email address:

Ho_yar40@yahoo.com( H. Yarahmadi)

\section{To cite this article:}

Hossein Yarahmadi, Ali bohloli. Analysis of Just in Time Prerequisites in Iranian Car Assembly Plants. Journal of Finance and Accounting. Vol. 3, No. 6, 2015, pp. 172-176. doi: 10.11648/j.jfa.20150306.11

\begin{abstract}
Just in time (hereafter JIT) has emerged as a key production management approach for cost effectiveness of a wide range of industrial sectors especially in car assembly plants. However, JIT implementation needs some basic prerequisites which organize the aim of this research. To do so, a questionnaire has been designed. The results show that Iranian car assembly plants listed in Tehran Stock Exchange (hereafter TSE) have extensive problems as customer-based, quality of supplied material and... For JIT implementation. Furthermore, they suffer from the problem of developing country, such as low cost of labor, lack of competence, high cost of imported technology and cost of quality.
\end{abstract}

Keywords: Just in Time, Car Assembly Plants, Tehran Stock Exchange

\section{Introduction}

Rapid change of the market's needs is a major feature of the current world. This phenomenon has forced researchers and practitioners to develop new production management techniques to cope with the changes in market places. JIT as a production management system is one of them. This system is designed for achieving continuous quality and productivity improvement through production with zero defects and spoilages. It was initially emerged in the Japanese anufacturing industry and implies that equipment, resources, materials and labor are to be available only in the amount required and at the time required. This system has been found to increase productivity,

Performance and quality in general and earning quality in special. Although, the management is able to make appropriate program, decision and control with implementation of this system.

Iranian car assembly plants play important role in the economy of this country because of providing employment opportunities. They have developed many programs for customer satisfaction in recent years. Unfortunately, they extensively criticized in adoption with new manufacturing systems and their programs aren't sufficient for survival and competence in global market. So in recent years, Iranian companies such as car assembly plants need new techniques because of economy decentralization matters, and law requirements, and try to be accepted in global markets. Therefore, they have to use new management techniques such as Activity Based Costing, Supply Chain Management, Quality Costing, Just in Time etc. This strategy provides a best customer satisfaction and increases stockholders' wealth. Since benefit from these techniques such as JIT needs some basic prerequisites and infrastructures, this article concentrates on these factors and foundations in Iranian car assembly plants which listed TSE.

The paper is organized as followed. Section II describes background of this study which contains JIT literature and its prerequisites for appropriate implementation.

Section III develops the methodology. Section IV concludes the paper.

\section{Literature Review}

Just in time (JIT)

JIT is one of the developed and advanced programming and planning systems. It is a special approach for developing and operating manufacturing system. This system was originated by Taiichi Ohno in Japan at Toyota car assembly plants and called Toyota system. In other words, it is the output of japans management system and has implemented in their companies since 1970, because of these countries special characteristics, such as low level of natural recourse. 
This system was used widely during oil shocks in 1973. Some researchers believe that, this shock and reducing of natural recourse, were the principal impetus in JIT implementation at that time. Another reason for developing this system in Japan is that the Japanese have high equality sense and group thinking. They consider themselves as a unit community and individual differences aren't recognized. (Cheng, 1990)

JIT can be defined as "a philosophy of manufacturing based on planned elimination of all waste and on continuous improvement of productivity" in the APICS dictionary. It's philosophy is known as reducing inventory and producing appropriate goods based on continuous checking of abnormal and spoilage products. It is defined as an approach with the objective of producing the right part in the right place at the right time. It satisfies internal and external customers. Because of high quality ordered production. This system, improves stockholders' wealth with reducing all inventory levels, scrap, rework and unnecessary moving of materials. In the past, JIT was known as reducing inventory level of Japanese' warehouse, but recently it has been developed as management philosophy, which comprises science, principles and production techniques. (Goddard, 1986) As such, tree goals are ensured in JIT implementation: to increase competitiveness; to increase productivity of production process; and to decrease time, working and material level of production process.

Studies on JIT implementation have generally found that this system increases profitability of companies. Gitman (2001) describes this system as an instrument for minimizing inventory investment. He finds that JIT makes efficiency for production, materials and shipment. Just in Time, Total Quality Management and Supply Chain Management represent alternative approaches to improve effectiveness and efficiency of an organization's operations (Vijay et al. 2005).

High quality production and productivity, decreasing production cycle, delivery lead times and reducing some costs (such as machinery set up) and space requirement are the benefits of this system implementation. Another benefits, is referred to more skilled workers and their high participation in production process. Based on Usan and Nanda (1995) research, JIT led to increase in earning per share, inventory turnover for each dollar sales and decrease labor cost. Kazazi and keller (1994) determined a lot of tangible and intangible benefits for JIT implementation in European manufacturing companies. Inman and Mehra (1993) recognized direct financial benefits as the best benefits derived from JIT implementation. They point out that JIT implementation can not be successful unless:

- every workforce participates in organization

- company and production process should be organized for maximum output and effectiveness

- production scheduling of, quality programs for customer satisfying and accountable and responsible for real demands.

Golhar and Stamm (1991) found that the success of JIT implementation depends on quality control, supplier participations, implementation and participation of labor in decision making and elimination of waste and spoilage. Also,
Marta (2001) shows that, JIT depends on logistics which include transportation, warehousing and several strategies for handling potential supply chain uncertainties.

It is worth pointing out that JIT implementation suffers from some weaknesses and constraints such as:

- Implementation is expensive and cannot be undertaken lightly.

- It eliminates conservatism reserve which plays safety inventory role for companies.

- Reduction of workforce in dependability.

At last, it is important to declare that, the industries of developing countries such as Iran, suffer from substantial productivity and quality problems. Therefore, they need to benefit from this system. Unfortunately, lack of this system had not been felt by Iranian companies because of centralized economies, existence of more governmental companies, lack of competence and unused large warehouse. Furthermore, the economy of Iran suffers from high inflation and real interest rate, high cost of quality and imported technology. Low cost of labors are the other characteristics of this economy.

According to studies, these characteristics are the important obstacles of JIT implementation. Some researches such as Emel et al. (2003) develop this issue in developing countries. Based on their done in Turkey, financial difficulties and demand uncertainties are the main obstacles of this system implementation.

It is interesting to state that, despite the successful implementation in Japan, other countries could not appropriately benefit from this system, Because of special environment of Japan. Other reasons, relate to some basic prerequisites of JIT implementation. These elements play important roles in JIT implementation. Otherwise this system cannot be effective. JIT includes some elements and parties such as work force, purchase, production process, planning and coordination in company.

These parties should be merged for JIT goal earning. (Goddared, 1986) From the Inman and

Mehra's (1993) view, 20 factors are essential in JIT implementation. They classified these factors in categories of production's strategy, suppliers' strategy, strategy of training and management committee.

Noori (1997) determined 72 factors in adaptation of manufacturing system with JIT system and classified them in 6 categories in Iran. Based on research of Sohel et al. (2003), some foundations such as labor policies, management quality, production technology and appropriate working system affect on relationship between JIT and effectiveness. Finally, the most important prerequisites of JIT implementation are:

a) Steady rate of production

b) Reducing inventory level

c) Reducing lead times

d) Flexible and more skilled work force

e) Confidential suppliers

f) Disciplined and responsible workforce

g) Preventive maintenance

h) High quality of material and inventory. 


\section{Methodology and Sample}

The main purpose of this study is to conduct and analyze existence of JIT implementation prerequisites in Iranian car assembly plants listed in TSE. As mentioned above, successful JIT implementation needs existence of key foundations and prerequisites. So that, without them, JIT can not be implemented appropriately.

Therefore, we developed following hypotheses to pursue our survey investigation:

H0: Iranian car assembly plants listed in TSE have appropriate prerequisites for JIT implementation

H1: Iranian car assembly plants listed in TSE haven't appropriate prerequisites for JIT implementation

These hypotheses focus mainly on overall evaluation of existence of JIT implementation in mentioned companies. As this implementation needs some prerequisites, the main hypothesis is detailed to the following sub-hypotheses for easy testing. On the other hand, the main prerequisites of JIT implementation are determined as sub-hypotheses:

1. Material suppliers are competitive.

2. Banks cooperate in opening of letter of credit.

3. Service renders are confidential

4. Service renders are competitive.

5. Productions have high quality.

6. These companies are competitive.

7. Set up time of production line is low.

8 . The machines are regulated rapidly.

9. The machines' regulation costs are low.

10. Production lines have a high flexibility.

11. Work forces are multi skills.

12. Work forces are trained continuously.

13. Work forces are responsible for quality.

14. Work forces have high cooperative spirit.

15. Customers are satisfied with product quality.

16. Production lines are developed continuously.

17. Customers are satisfied with product prices.

18. These companies produce diversified products.

19. Material suppliers are required to deliver qualitative materials.

20. Material suppliers are required to have on time delivery of materials.

21. Delivery of materials, are coordinated with delivery of products to end users.

22. There is coordination between materials' transformation and products' delivery to end users.

23. There isn't any financial problem for opening of letter of credit.

24. The management emphasizes on prevention and maintenance matters.

25. Production program can be developed in a specified time horizon.

26. Customers are satisfied with diversified production.

The questionnaire survey method was applied in this study, because it is a practical approach to obtain empirical evidence for getting information about existence of appropriate and necessary prerequisites for JIT implementation. After a review of the literature, discussions with practitioners, key above mentioned prerequisites were designed as questionnaire which included 26 detailed questions.

Target population of this survey was financial specialists and middle management of Iranian car assembly plants. The response to each question statement was designed as "strongly disagree" to "strongly agree" expressed a Likert scale of 1 to 5 while "average" indicated by the score of 3. Questions were worded with a view of achieving a high degree of validity. This questionnaire was pre-tested and necessary questions reworded.

In order to check questionnaire's reliability, we calculate Cronbach's á. Its number (66\%) shows the appropriate reliability of this instrument. Furthermore, $\mathrm{T}$ test was used for analysis of uestionnaires' responses. Therefore, after gathering questionnaires' responses, they were valued in SPSS, and analyzed for testing the subhypothesis.

\section{Descriptive Statistics and Results Discussion}

Table 1. Descriptive statistics of questionnaires responses.

\begin{tabular}{|c|c|}
\hline 1 & Material suppliers are competitive. 152.60214435 \\
\hline 2 & The banks cooperate in opening of letter of credit 253.40531529 \\
\hline 3 & Service renders are confidential 153.06323829 \\
\hline 4 & Service renders are competitive. 152.85293832 \\
\hline 5 & Productions have high quality 142.0367421 \\
\hline 6 & These companies are competitive 152.38185329 \\
\hline 7 & Set up time of production line is low. 142.47125929 \\
\hline 8 & The machines are regulated rapidly 142.50155035 \\
\hline 9 & The machines' regulation costs are low 142.59214732 \\
\hline 10 & Production lines have a high flexibility. 142.2096526 \\
\hline 11 & Work forces have multi skills 142.29126524 \\
\hline 12 & Work forces are trained continuously 142.82294129 \\
\hline 13 & Work forces are responsible for quality 142.20127118 \\
\hline 14 & Work forces have high cooperative spirit. 142.70244135 \\
\hline 15 & Customers are satisfied with product quality. 141.796859 \\
\hline 16 & Production lines, develop continuously 142.73294426 \\
\hline 17 & Customers are satisfied with product prices. 141.763889 \\
\hline 18 & These companies produce diversified products. 242.94263241 \\
\hline 19 & $\begin{array}{l}\text { Material suppliers, are required to deliver qualitative materials } 142.94 \\
353826\end{array}$ \\
\hline 20 & $\begin{array}{l}\text { Requirement of material suppliers on time delivery of materials. } 24 \\
2.82264429\end{array}$ \\
\hline 21 & $\begin{array}{l}\text { Materials delivery, are coordinated with products delivery to end users. } \\
142.38156521\end{array}$ \\
\hline 22 & $\begin{array}{l}\text { Transformation of materials are coordinated with products delivery to } \\
\text { end users. } 142.62265024\end{array}$ \\
\hline 23 & $\begin{array}{l}\text { There isn't any financial problem in opening of letter of credit } 242.90 \\
294429\end{array}$ \\
\hline 24 & $\begin{array}{l}\text { The management emphasize on preventive and maintenance. } 142.47 \\
215921\end{array}$ \\
\hline 25 & $\begin{array}{l}\text { Production program can be developed in a determined horizon time } 14 \\
2.89322938\end{array}$ \\
\hline & Customers are satisfied with diversified production 142.29127118 \\
\hline
\end{tabular}

Note: 1) All questions are stated in abbreviated or truncated form. 2) Means are determined based on a Likert scale of 1 to 5.i.e. from "strongly disagree" to "strongly agree" while "3" indicate "Neutral". 3). The scores of "4" and "5" are combined for calculating the percentage of "agree" group which shown in Column (4). Column (5) shows percentage of "disagree" group which calculated from combination of scores "1"and"2". Column (6) indicates neutral percentage of responses show significant level and t value. 
Table-1 summarizes the main descriptive statistics which derived from questionnaires' responses. Over the respondents' view, $62 \%$ of sub-hypotheses were significant and $38 \%$ of them weren't significant in mentioned confidence level (95\%) which detailed in table-2. According to these findings, Iranian car assembly plants listed in TSE contain only $38 \%$ of JIT implementation's prerequisites. However, since these companies haven't all required prerequisites, then the main hypothesis wasn't accepted. On the other hand, Iranian car assembly plants listed in TSE haven't appropriate prerequisites for JIT implementation.

According respondents' responses, Material suppliers, are required on time delivery of qualitative materials. These companies haven't any problems with service renders, Because of their confidence and competitiveness. Production lines and programs are continuously developed in these companies. High cooperative spirit of workforce is another characteristic of mentioned companies and these workforces are trained continuously.

These companies had considerable success in products' diversification. Contrary to existence of sales' problem in car assembly plants of global markets, Iranian mentioned companies haven't any problems in this area. Because, Iranian government, charges high customs to cars imported, and protects domestic productions.

Table 2. Analysis of sub-hypotheses (95\% confidence).

\section{Questionnaires S.D Sig t}

1 Material suppliers are competitive. $1.070 .046-2.08$

2 The banks cooperate in opening of letter of credit 0.780 .0043 .07

3 Service renders are confidential 1.040 .7440 .33

4 Service renders are competitive. $1.100 .443-0.78$

$5 \quad$ Productions have high quality $0.870 .000-6.51$

6 These companies are competitive $0.990 .001-3.66$

7 Set up time of production line is low. $0.790 .000-3.92$

8 The machines are regulated rapidly $0.930 .004-3.14$

9 The machines' regulation costs are low $0.990 .021-2.43$

10 Production lines have a high flexibility. $0.910 .000-5.07$

11 Work forces have multi skills $0.910 .000-4.55$

12 Work forces are trained continuously $0.940 .280-1.10$

13 Work forces are responsible for quality $0.910 .000-5.07$

14 Work forces have high cooperative spirit. $0.970 .086-1.77$

15 Customers are satisfied with product quality. $0.840 .000-8.32$

16 Production lines, develop continuously $1.020 .141-1.51$

17 Customers are satisfied with product prices. $0.740 .000-9.72$

18 These companies produce diversified products. $0.780 .661-0.44$

19 Material suppliers, are required to deliver qualitative materials 0.92 $0.711-0.37$

20 Requirement of material suppliers on time delivery of materials. 0.83 $0.226-1.23$

21 Materials' delivery, are coordinated with products' delivery to end users. $0.890 .000-4.06$

22 Transformation of materials, are coordinated with products delivery to end users. $1.040 .040-2.13$

23 There isn't any financial problem in opening of letter of credit 0.84 $0.422-0.81$

24 Management emphasize on preventive and maintenance. 0.990 .004 $-3.11$

Production program can be developed in a determined horizon time $1.040 .513-0.66$

26 Customers are satisfied with diversified production. $0.840 .000-4.92$

This survey remarks some other important matters. These companies and their materials' Suppliers aren't competitive, because of Iranian centralized economy. In spite of governmental protections and high domestic customers, delivery of materials and its transformation aren't coordinated with products' delivery to end users. Although these companies are developed in recent decade, their customers haven't appropriately been satisfied with prices, diversifications and qualities. Furthermore, these companies must have high attention to prevention, maintenance and machine's regulation time. They not only have to reduce the cost of production but also increase flexibility of Production lines. Finally, their work forces must have multi skills.

\section{Conclusions}

As mentioned above, successful implementation of JIT needs existence of some necessary prerequisites such as better quality products, responsibility of every workforce, reduced spoilage, reduced rework, reduced cycle times, lower setup times, less inventory, cost savings etc. Therefore, this article was accomplished for analysis and determining of these prerequisites existence. According to the data collected, Iranian car assembly plants listed in TSE haven't basic problems in the aspects such as on time delivery qualitative materials from suppliers, finance for opening of letter of credit, Service renders, diversified products producing, continuously development of Production lines, Development of Production program, continuously training of Workforces and their high cooperative spirit. However, these companies suffer from lack of some important characters which must be considered for appropriate mplementation of JIT. Un competitive of these companies and material suppliers, High cost and time of machines regulation, High set up time of production line, low flexibility of Production lines, Low customer satisfaction of product quality and high prices are major problems of these companies. Transformation of materials and their delivery aren't coordinated with products delivery to end users. Work forces of these companies don't have multi skills. Due to the importance of these factors, mentioned companies have to pay high attention to these prerequisites for successful JIT implementation. In addition to mentioned problems, JIT implementation was threatened with other problems such as high inflation and real interest rate, high cost of imported technology, high cost of quality, low cost of labor, and lack of competence which related to developing countries. As the implementation of JIT could help these companies in cost decreasing, both the management of these companies and government should take a sufficient program for betterment of these foundations. The government can help these companies with policies such as financial incentives, shifting of tax payment to future and bear of some implementation costs.

\section{Reference}

[1] Cheng T. 1990. A state of the art review of JIT production. Advanced Manufacturing Engineering, 2 (2): 96-102. 
[2] Emel L, Gulgun, M-st-koglub and Ercan E. 2003. JIT in developing countries - a case study of the Turkish prefabrication sector. Building and Environment 38(6): 853 860. doi:10.1016/S0360-1323(03)00021-0

[3] Golhar D.Y, Stamm C.L. 1991. The just-in-time philosophy: a literature review. International Journal of Production Research 29(4): 657-676

[4] Gitman L, Horngren C, Harrison W and Bamber L. 2001. Financial Analysis for Managers. Boston: Pearson Custom Publishing.

[5] Goddard W. 1986. Just-In-Time: Oliver Wight Publications, Brattleboro, VT.

[6] Huson M, Nanda D. 1995. The impact of just-in-time Accounting and Finance, and the Ohio CPA Journal. manufacturing on firm performance in the US. Journal of Operations Management 12(3-4): 297-310

[7] Inman R, Mehra S, . 1990. The transferability of Just-in-Time concepts to American small business. Interfaces 20 (2): 30-37.

[8] Inman R, Mehra S. 1993. Financial justification of JIT implementation. International Journal of Operations \& Production Management 13(4):.32-39.

[9] Kazazi A, Keller A,. 1994. Benefits derived from just-in-time by European manufacturing companies. Industrial Management \& Data Systems 94(10):12-15.

[10] Keller A, Kazazi A. 1993. Just-in-Time manufacturing systems: a literature review. Industrial Management \& Data Systems 93(7): 1-32.
[11] Lee S, Ebrahimpour M. 1985. An analysis of Japanese quality control systems: implications for American manufacturing firms. SAM Advanced Management Journal 50(2): 24-31.

[12] Martha, Joseph and Sunil S. 2001. When Just in Time Becomes Just In Case. The Wall Street Journal. October 22, A18.

[13] Noori, S. 1995. Determining of compatibility degree of industrial unit with JIT system and its applicability in car assembly plants. MS thesis, Tarbiat Modares university (iran)

[14] Sohel A, Roger G, Schroeder and Kingshuk K. 2003. The role of infrastructure practices in the effectiveness of JIT practices: implications for plant competitiveness. Journal of Engineering and Technology Management 20(3):161-195

[15] Vijay R, Kannan, K. 2005. Just in time, total quality management, and supply chain management: understanding their linkages and impact on business performance. The international journal of management science omega 33(2) :153-162.

[16] David Boansi. Yield Response of Rice in Nigeria: A Co-Integration Analysis. American Journal of Agriculture and Forestry. Vol. 2, No. 2, 2014, pp. 15-24. doi: 10.11648/j.ajaf.20140202.11

[17] Roland Nuhu Issaka, Moro Mohammed Buri, Satoshi Nakamura, Satoshi Tobita. Comparison of Different Fertilizer Management Practices on Rice Growth and Yield in the Ashanti Region of Ghana. Agriculture, Forestry and Fisheries. Vol. 3, No. 5, 2014, pp. 374-379. doi: 10.11648/j.aff.20140305.17. 